\title{
Peroxisome Proliferator-Activated Receptor Gamma Coactivator 1-Beta
}

National Cancer Institute

\section{Source}

National Cancer Institute. Peroxisome Proliferator-Activated Receptor Gamma

Coactivator 1-Beta. NCI Thesaurus. Code C101768.

Peroxisome proliferator-activated receptor gamma coactivator 1-beta (1023 aa, 113 $\mathrm{kDa}$ ) is encoded by the human PPARGC1B gene. This protein is involved in both estrogen receptor signaling and transcriptional activation. 